\title{
Synthesis and Application of Polymerizable Silicone Oligomers from Water Glass
}

\author{
Yoshiki Chujo, Toshiaki SHISHINO, and Yuya YAMASHITA \\ Department of Synthetic Chemistry, Faculty of Engineering, Nagoya University, \\ Furo-cho, Cikusa-ku, Nagoya 464, Japan
}

(Received February 3, 1984)

\begin{abstract}
Polymerizable methacryloyl- or epoxy-end silicone oligomers were prepared from water glass by two methods. i) Silicic acid, which was prepared by acidification of aqueous water glass, was end-capped with methyldichloro(3-methacryloyloxypropyl)silane and trimethylchlorosilane. ii) Silicic acid was allowed to react with dimethylchlorosilane and trimethylchlorosilane and then subjected to hydrosilylation with allyl methacrylate or allyl glycidyl ether. The methacryloyl-end silicone oligomers were copolymerized with methyl methacrylate to produce soluble and film-forming copolymers. Addition of only $1 \mathrm{wt} \%$ of the copolymers to PMMA showed high water-repellency on the air side of the film. The methacryloyl-end silicone oligomers were also subjected to coating on various test panels followed by curing with UV or electron beam irradiation.
\end{abstract}

KEY WORDS Silicone Oligomers / Water Glass / Hydrosilylation / Water-

Repellency / Coatings /

Recently considerable interest has been shown in the development of functional organic materials. We have synthesized tailormade graft copolymers by the macromonomer method for the purpose of functionalization of polymers. $^{1}$ Since Lentz reported ${ }^{2}$ the trimethylsilylation of water glass to prepare functional organic materials from mineral resources, the synthesis of soluble silicone oligomers have been actively investigated ${ }^{3}$ and reviewed by Currell. ${ }^{4}$ Recently, Inoue et al. reported the preparation and copolymerization of carbon-functional silylated silicic acid by the silylation of water glass. ${ }^{5}$

Polysiloxane- or silicone-containing copolymers are of interest for a number of reasons including a wide temperature range over which they retain elasticity, ${ }^{6}$ their thermal, UV and oxidative stabilities, low surface energies, bio-compatibility ${ }^{7}$ and high oxygen permeabilities. $^{8}$

Here, we report the synthesis of polymerizable silicone oligomers by the novel hydro- silylation of allyl methacrylate or allyl glycidyl ether with silicone oligomers having $\mathrm{Si}-\mathrm{H}$ bonds at terminal positions and also by the end-capping method. Furthermore, for application of the polymerizable silicone oligomers, we have examined the graft copolymerization with methyl methacrylate and cross-linking reactions to give hard coats.

\section{RESULTS AND DISCUSSION}

The preparation of polymerizable silicone oligomers was carried out according to Scheme 1.

\section{Method I}

After acidification of aqueous water glass, silicic acid was extracted with THF in the presence of sodium chloride. The introduction of polymerizable end groups was carried out by the reaction with dichloromethyl(3-methacryloyloxypropyl)silane (1). 1 was prepared by hydrosilylation of allyl methacrylate 
Method I

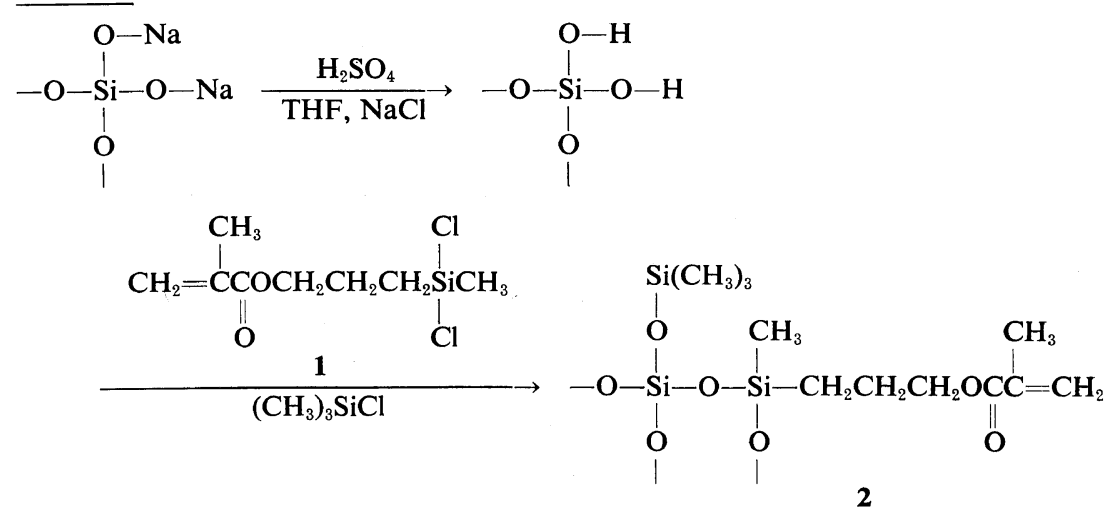

Method II
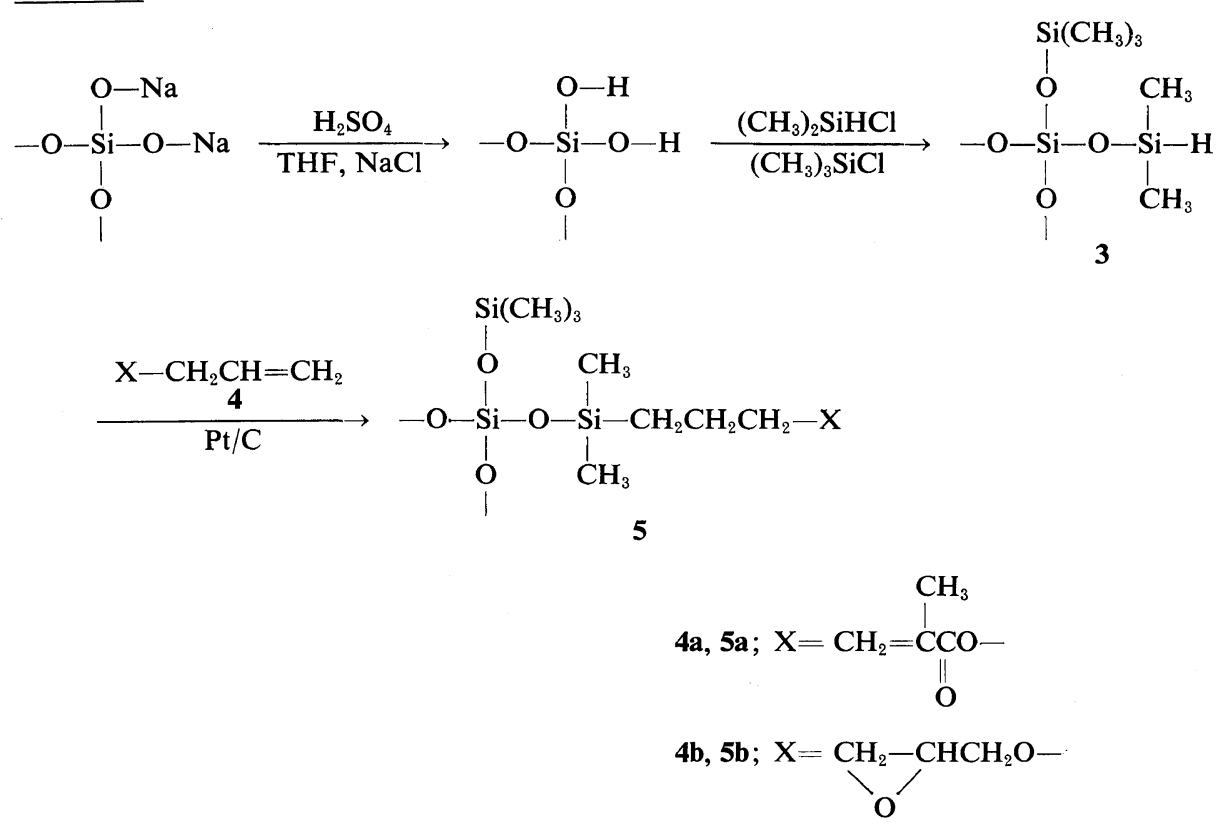

Scheme 1.

with dichloromethylsilane catalyzed by $\mathrm{Pt} / \mathrm{C}$ in trimethylchlorosilane and $\mathbf{1}$ in $\mathrm{THF}$ at room the presence of hydroquinone as the inhibitor temperature and then at the reflux temperature (eq 1) and identified by IR and ${ }^{1} \mathrm{H}$ NMR to produce polymerizable silicone oligomers spectroscopies (see the experimental part).

(2a). The IR spectrum of $\mathbf{2 a}$ shows a charac-

The extracted silicic acid was treated with teristic band at $3400 \mathrm{~cm}^{-1}$ due to the re-

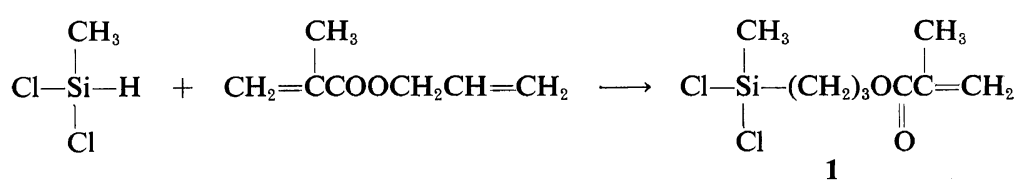


Table I. Changes in the molecular weight and number of methacryloyl-end groups before and after the second treatment of $\mathbf{2 a}$ with trimethylchlorosilane

\begin{tabular}{|c|c|c|c|c|c|c|c|c|}
\hline \multirow{3}{*}{ No. ${ }^{x}$} & \multicolumn{4}{|c|}{ Before (2a) } & \multicolumn{4}{|c|}{ After (2b) } \\
\hline & \multicolumn{2}{|c|}{$\mathrm{GPC}^{\mathrm{b}}$} & \multirow{2}{*}{$\begin{array}{c}\mathrm{VPO}^{\mathrm{c}} \\
M_{n}\end{array}$} & \multirow{2}{*}{$\begin{array}{l}\text { End }^{d} \\
\text { group }\end{array}$} & \multicolumn{2}{|c|}{$\mathrm{GPC}^{\mathrm{b}}$} & \multirow{2}{*}{$\begin{array}{c}\mathrm{VPO}^{\mathrm{c}} \\
M_{n}\end{array}$} & \multirow{2}{*}{$\begin{array}{l}\text { End }{ }^{d} \\
\text { group }\end{array}$} \\
\hline & $M_{n}$ & $M_{w} / M_{n}$ & & & $M_{n}$ & $M_{w} / M_{n}$ & & \\
\hline 2 & 1970 & 1.2 & 2760 & 3.9 & 2190 & 1.3 & 3040 & 3.3 \\
\hline 5 & 2420 & 1.4 & 2780 & 1.5 & 2650 & 1.4 & 2960 & 1.1 \\
\hline
\end{tabular}

a Sample numbers correspond to those in Table II.

b Measured in THF using a calibration curve with polystyrene.

c Measured in benzene.

d Determined in THF by UV spectroscopy.

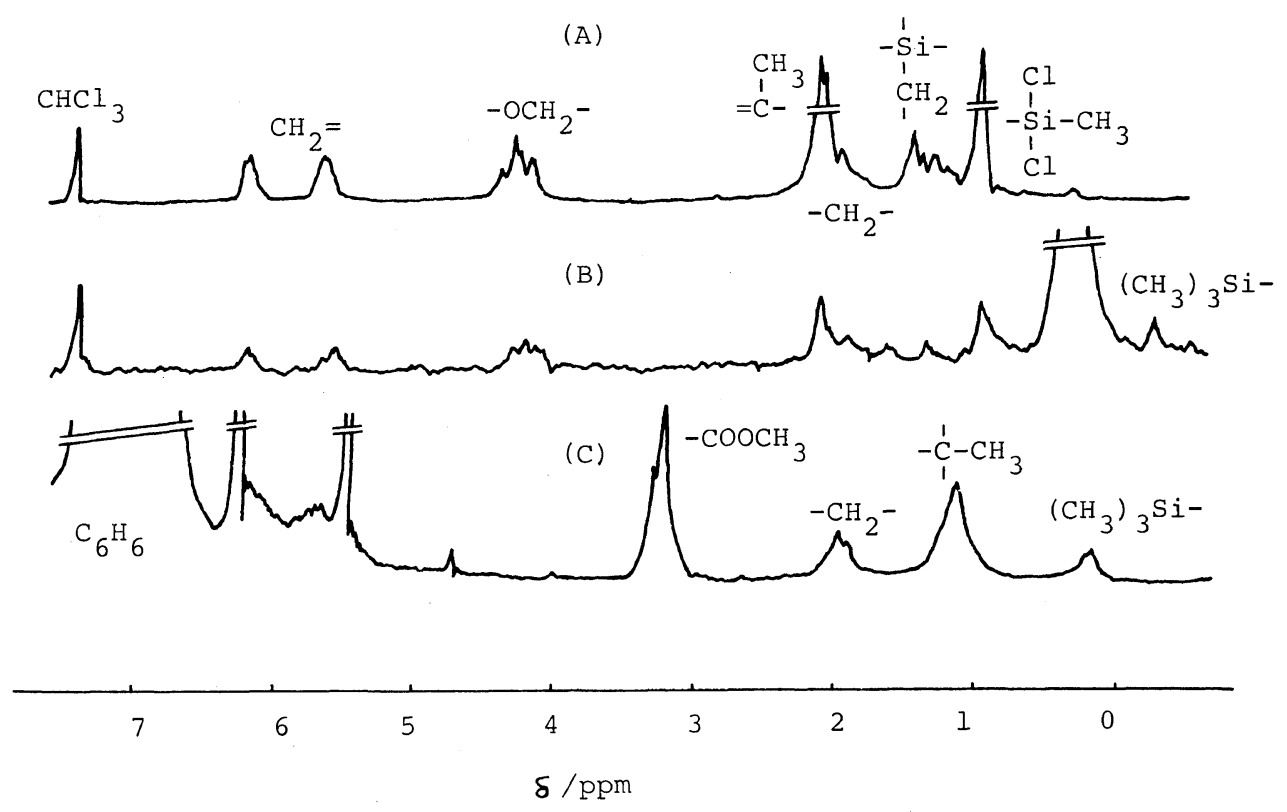

Figure 1. ${ }^{1} \mathrm{H}$ NMR spectra of A, 1; B, silicone oligomers (2b); and C, copolymer (6).

maining silanol group. This band disappeared by the treatment of $\mathbf{2 a}$ with trimethylchlorosilane once more. As shown in Table I, the molecular weight and number of the end groups were little changed between before (2a) and after (2b) the second treatment with trimethylchlorosilane. The structure of $\mathbf{2 b}$ was confirmed by IR and ${ }^{1} \mathrm{H}$ NMR spectroscopies. The IR spectrum of $\mathbf{2} \mathbf{b}$ shows absorptions at $1720 \mathrm{~cm}^{-1}\left(v_{\mathrm{C}=\mathrm{O}}\right), 1600 \mathrm{~cm}^{-1}\left(v_{\mathrm{C}=\mathrm{C}}\right)$,
$1420 \mathrm{~cm}^{-1}\left(\delta_{\mathrm{C}=\mathrm{C}}\right), 1250 \mathrm{~cm}^{-1}\left(\delta_{\mathrm{Si}-\mathrm{C}}\right)$, and $1090 \mathrm{~cm}^{-1}\left(v_{\mathrm{Si}-\mathrm{O}-\mathrm{Si}}\right)$. The presence of the end methacryloyl group was also supported from the ${ }^{1} \mathrm{H}$ NMR spectrum as shown in Figure 1. Elemental analysis showed that 2b contained no chlorine. This indicates that the $\mathrm{Si}-\mathrm{Cl}$ bond in $\mathbf{2 b}$ was hydrolyzed to the $\mathrm{Si}-\mathrm{OH}$ or $\mathrm{Si}-\mathrm{O}-\mathrm{Si}$ group. $\mathbf{2 b}$ was soluble in THF, benzene and chloroform. Relatively linear structure of $\mathbf{2 b}$ is supported by the 
Y. Chujo, T. Shishino, and Y. Yamashita

Table II. Preparation of methacryloyl-end silicone oligomers (2b) by method I

\begin{tabular}{|c|c|c|c|c|c|c|c|c|c|c|c|}
\hline \multirow{2}{*}{ No. } & \multirow{2}{*}{$\frac{\mathrm{WG}^{\mathrm{a}}}{\mathrm{g}(\mathrm{mmol})}$} & \multirow{2}{*}{$\frac{\text { Time }^{\mathrm{b}}}{\mathrm{h}}$} & \multicolumn{3}{|c|}{ End-cap $^{c}$} & \multicolumn{2}{|c|}{ Reflux Yield ${ }^{\mathrm{g}}$} & \multicolumn{2}{|c|}{$\mathrm{GPC}^{\mathrm{h}}$} & \multirow{2}{*}{$\begin{array}{c}\mathrm{VPO}^{\mathrm{i}} \\
M_{n}\end{array}$} & \multirow{2}{*}{$\begin{array}{l}\text { End }^{j} \\
\text { group }\end{array}$} \\
\hline & & & $1^{\mathrm{d}} / \mathrm{WG}$ & $\mathrm{TMCS}^{\mathrm{e}} / \mathrm{WG}$ & Add. ${ }^{\mathrm{f}}$ & $\mathrm{h}$ & $\mathrm{g}$ & $M_{n}$ & $M_{w} / M_{n}$ & & \\
\hline 1 & $.0 .83(2.4)$ & 0.5 & 3.5 & 3.2 & A & 2 & 0.39 & 1550 & 1.6 & 2060 & 4.8 \\
\hline 2 & $5.51(16)$ & 3 & 0.16 & 3.1 & $\mathrm{~A}$ & 4 & 2.33 & 2190 & 1.3 & 3040 & 3.3 \\
\hline 3 & $5.54(16)$ & 3 & 0.16 & 3.1 & $\mathrm{~B}$ & 4 & 2.58 & 2260 & 1.2 & 2100 & 0.27 \\
\hline 4 & $5.59(16)$ & 6 & 0.16 & 3.2 & B & 4 & 2.29 & 3360 & 1.6 & & 0.27 \\
\hline 5 & $5.54(16)$ & 3 & 0.19 & 3.1 & $\mathrm{C}$ & 6 & 2.51 & 2650 & 1.4 & 2960 & 1.1 \\
\hline 6 & $5.85(17)$ & 6 & 0.19 & 3.0 & $\mathrm{C}$ & 4 & 3.14 & 3220 & 1.4 & & 2.5 \\
\hline 7 & $11.14(32)$ & 4 & 0.19 & 3.1 & $\mathrm{C}$ & 4 & 6.72 & 2770 & 1.4 & & 1.1 \\
\hline 8 & $11.33(33)$ & 6 & 0.19 & 3.0 & $\mathrm{C}$ & 4 & 6.59 & 2730 & 1.3 & & 1.2 \\
\hline
\end{tabular}

a Water glass (JIS 1st class, $\mathrm{Na}_{2} \mathrm{O} \cdot 2.11 \mathrm{SiO}_{2}$ ).

b Acidolysis was carried out with $0.64 \mathrm{~mol}^{-1} \mathrm{H}_{2} \mathrm{SO}_{4}$ aq $(30 \mathrm{ml})$ at room temperature.

c Molar ratios.

d End-cap agent. Dimethylchloro(3-methacryloyloxypropyl)silane.

e Trimethylchlorosilane.

f Order of the addition. A, i) 1 ii) TMCS; B, i) TMCS ii) 1; C, at the same time.

g After reprecipitation from THF into methanol-water $(4: 1)$ and washing.

h Measured in THF using a calibration curve with polystyrene.

i Measured in benzene.

j Determined by UV spectroscopy in THF.

solubility in common organic solvents and also by the preliminary result of ${ }^{29} \mathrm{Si} \mathrm{NMR}$ spectroscopy. The results of the preparation of $\mathbf{2} \mathbf{b}$ are summarized in Table II. The molecular weight of $\mathbf{2 b}$ was dependent on the stirring time after acidification of water glass as evident from the results of No. 3 and No. 4 in Table II. However, as shown in Figure 2, a long stirring time caused a wide and bimodal distribution of the molecular weight. The number of end methacryloyl groups was dependent on the order of addition of 1 and trimethylchlorosilane. Simultaneous addition of $\mathbf{1}$ and trimethylchlorosilane produced silicone oligomers with about one end-functional group per molecule. This silicone oligomers can be used as macromonomers.

\section{Method II}

As shown in Scheme 1, polymerizable silicone oligomers were also prepared by method II. Silicic acid obtained after acidification of water glass was allowed to react with trimethylchlorosilane and dimethylchlorosilane.

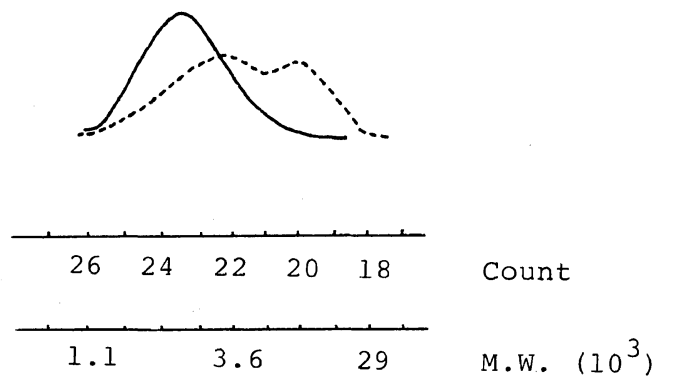

Figure 2. GPC traces of silicone oligomers (2b). (No. 3);----, (No. 4).

The silicone oligomers (3) shows a characteristic stretching band at $2130 \mathrm{~cm}^{-1}$ due to the $\mathrm{Si}-$ $\mathrm{H}$ bond in its IR spectrum. The results of the formation of 3 are summarized in Table III. The number of $\mathrm{Si}-\mathrm{H}$ groups determined by titration is close to the calculated value from the IR spectrum.

3 was treated with allyl methacrylate at $160^{\circ} \mathrm{C}$ in the presence of $\mathrm{Pt} / \mathrm{C}$ and hydroquinone to give $\mathbf{5 a}$ after precipitation in $\mathrm{MeOH}-\mathrm{H}_{2} \mathrm{O}$ (4:1). The IR spectrum of 5a shows characteristic bands owing to the methacryloyl group but no $\mathrm{Si}-\mathrm{H}$ absorption. 
Table III. Preparation of silicone oligomers with $\mathrm{Si}-\mathrm{H}$ bonds (3)

\begin{tabular}{|c|c|c|c|c|c|c|c|c|}
\hline \multirow{2}{*}{ No. } & \multirow{2}{*}{$\frac{\mathrm{WG}^{\mathrm{a}}}{\mathrm{g}}$} & \multirow{2}{*}{$\frac{\text { Time }^{b}}{h}$} & \multicolumn{2}{|c|}{ Molar ratio } & \multirow{2}{*}{$\frac{\text { Yield }^{\mathrm{e}}}{\mathrm{g}}$} & \multirow{2}{*}{$\begin{array}{c}\mathrm{VPO}^{\mathrm{f}} \\
M_{n}\end{array}$} & \multicolumn{2}{|c|}{$\mathrm{Si}-\mathrm{H}$} \\
\hline & & & $\mathrm{DMCS}^{\mathrm{c}} / \mathrm{WG}$ & $\mathrm{TMCS}^{\mathrm{d}} / \mathrm{WG}$ & & & $\mathrm{IR}^{\mathrm{g}}$ & Tit. $^{h}$ \\
\hline 1 & 5.56 & 6 & 1.3 & 2.3 & 2.93 & 4600 & 3.4 & 3.4 \\
\hline 2 & 5.54 & 6 & 2.0 & 2.3 & 2.59 & 4200 & 1.8 & 2.6 \\
\hline 3 & 5.56 & 6 & 1.9 & 2.3 & 3.00 & 4200 & 3.7 & 3.8 \\
\hline 4 & 5.54 & 6 & 2.0 & 2.3 & 2.55 & 5200 & 3.0 & 3.1 \\
\hline
\end{tabular}

a Water glass (JIS 1st class, $\mathrm{Na}_{2} \mathrm{O} \cdot 2.11 \mathrm{SiO}_{2}$ ).

b Acidolysis was carried out with $0.64 \mathrm{~mol} \mathrm{l}^{-1} \mathrm{H}_{2} \mathrm{SO}_{4}$ aq $(30 \mathrm{ml})$ at room temperature.

c Dimethylchlorosilane.

d Trimethylchlorosilane.

e After reprecipitation from THF into methanol-water (4:1) and washing.

f Measured in benzene.

g The number of $\mathrm{Si-H}$ groups per molecule was determined by IR spectroscopy using a calibration curve with tetramethyldisiloxane.

${ }^{\mathrm{h}}$ Determined by titration with mercuric acetate in methanol.

Table IV. Preparation of silicone oligomers (5a and $\mathbf{5 b})$ by method II

\begin{tabular}{|c|c|c|c|c|c|c|c|c|}
\hline \multirow{2}{*}{ No. } & \multirow{2}{*}{$\frac{4}{g}$} & \multicolumn{3}{|c|}{3} & \multirow{2}{*}{$\frac{\text { Temp }}{{ }^{\circ} \mathrm{C}}$} & \multirow{2}{*}{$\frac{\text { Yield }^{\mathrm{c}}}{\mathrm{g}}$} & \multirow{2}{*}{$\begin{array}{c}\mathrm{VPO}^{\mathrm{d}} \\
M_{n}\end{array}$} & \multirow{2}{*}{$\begin{array}{l}\text { End } \\
\text { group }\end{array}$} \\
\hline & & $\mathrm{g}$ & $M_{n}{ }^{\mathrm{a}}$ & $\mathrm{Si}-\mathrm{H}^{\mathrm{b}}$ & & & & \\
\hline 1 & a 2.14 & 2.00 & 4200 & 2.6 & 60 & 1.21 & 6300 & $0.31^{\mathrm{e}}$ \\
\hline 2 & a 4.99 & 2.00 & 5200 & 3.1 & 160 & 1.01 & 7700 & $1.7^{\mathrm{e}}$ \\
\hline 3 & b 0.59 & 2.00 & 4200 & 3.8 & 80 & 1.43 & 4300 & $0^{\mathrm{f}}$ \\
\hline 4 & b 1.66 & 2.00 & 4600 & 3.4 & 160 & 1.39 & 5300 & $3.3^{\mathrm{f}}$ \\
\hline
\end{tabular}

${ }^{a}$ Determined by VPO in benzene.

b Determined by titration with mercuric acetate in methanol.

c After reprecipitation from THF into methanol-water (4:1) and washing.

d Measured in benzene.

e Determined by UV spectroscopy.

${ }^{f}$ Determined by ${ }^{1} \mathrm{H}$ NMR spectroscopy.

Similarly, the reaction of 3 with allyl glycidyl ether at $160^{\circ} \mathrm{C}$ produced epoxy-end silicone oligomers $(\mathbf{5 b})$. The structure of $\mathbf{5 b}$ was confirmed by IR and ${ }^{1} \mathrm{H}$ NMR spectroscopies. Because epoxy groups are sensitive to $\mathrm{Si}-\mathrm{Cl}$ bonds, the introduction of epoxy-end groups can be carried out only by method II. The results of the formation of silicone oligomers (5a and $\mathbf{5 b}$ ) are summarized in Table IV. As can be seen in Table IV, the introduction of the end group was ineffective at $60-80^{\circ} \mathrm{C}$ (No. 1 and No. 3). In these cases, the absorptions due to $\mathrm{Si}-\mathrm{H}$ bonds remained in their IR spectra.

\section{Copolymerization with Methyl Methacrylate}

The silicone oligomers with one end-functional group can be used as macromonomers to form graft copolymers. Methacryloyl-end silicone oligomers $\mathbf{2 b}$ were copolymerized with methyl methacrylate in the presence of AIBN as the initiator in benzene at $60^{\circ} \mathrm{C}$ as shown in eq 2 . The copolymer was isolated by reprecipitation from benzene into $\mathrm{MeOH}-$ diethyl ether $(1: 1)$, which dissolves unreacted $\mathbf{2 b}$. The removal of unreacted $\mathbf{2 b}$ was supported by GPC analysis. The structure of the copoplymer (6) was confirmed by IR 


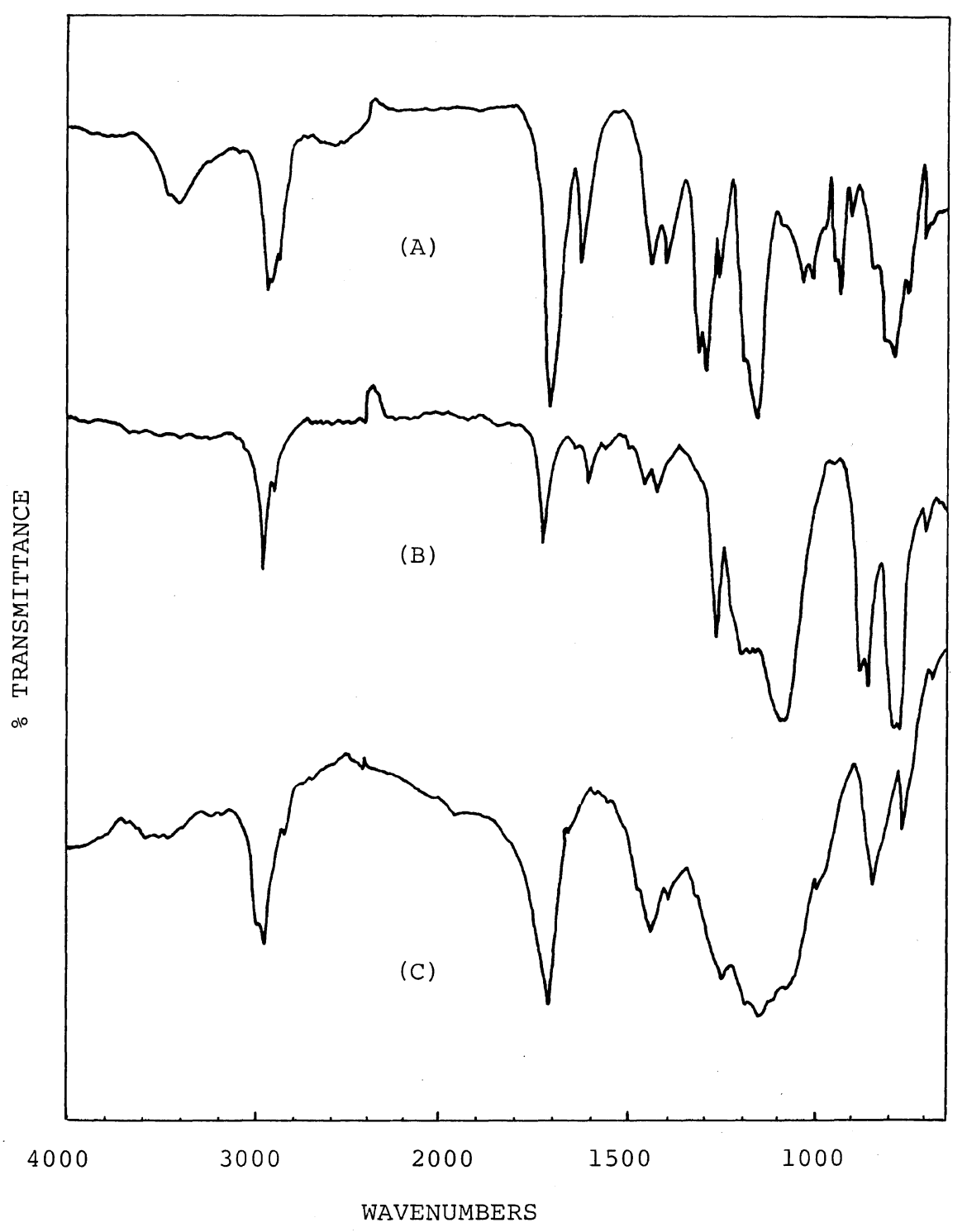

Figure 3. IR spectra of $1(A), 2 b(B)$, and $6(C)$.

(Figure 3C) and ${ }^{1} \mathrm{H}$ NMR (Figure $1 \mathrm{C}$ ) spectroscopies. 6 was soluble in THF, benzene and gave films by casting a THF solution. The results of the copolymerization are summarized in Table V.

\section{Application of Silicone Oligomers}

Water repellency of $\mathbf{6}$ was evaluated by the measurement of contact angles for water by the sessile drop method. PMMA films containing various amounts of PMMA-polysiloxane graft copolymer 6 were cast from a THF solution onto clean glass slides. The results are shown in Figure 4. On the air side of the film, the contact angle on the copolymer 6 alone was $100^{\circ}$, which shows high water repellency. As shown in Figure 4, this property is also attained by adding 6 to PMMA. Only $1 \mathrm{wt} \%$ 
Polymerizable Silicone Oligomers from Water Glass

Table V. Copolymerization of methacryloyl-end silicone oligomers (2b) with methyl methacrylate

\begin{tabular}{|c|c|c|c|c|c|c|c|c|}
\hline \multirow{3}{*}{ No. } & \multicolumn{3}{|c|}{ Monomer } & \multirow{3}{*}{$\begin{array}{c}\begin{array}{c}\text { AIBN } \\
\left(\times 10^{2}\right)\end{array} \\
\mathrm{mol} \mathrm{l}^{-1}\end{array}$} & \multirow{3}{*}{$\frac{\text { Time }}{\mathrm{h}}$} & \multicolumn{3}{|c|}{ Copolymer } \\
\hline & \multirow{2}{*}{$\frac{\mathrm{MMA}}{\mathrm{mol} \mathrm{1}^{-1}}$} & \multicolumn{2}{|c|}{ Silicone Oligomer } & & & \multirow{2}{*}{$\frac{\text { Yield }^{\mathrm{c}}}{\%}$} & \multicolumn{2}{|c|}{$\mathrm{GPC}^{\mathrm{d}}$} \\
\hline & & No. ${ }^{b}$ & $\left(\times 10^{2}\right) \mathrm{mol} \mathrm{l}^{-1}$ & & & & $M_{n}\left(\times 10^{-4}\right)$ & $M_{w} / M_{n}$ \\
\hline 1 & 5.54 & 2 & 3.67 & 1.35 & 5 & 28 & 11.6 & 2.6 \\
\hline 2 & 5.61 & 3 & 3.73 & 1.33 & 2 & 16 & 10.5 & 2.0 \\
\hline 3 & 2.38 & 5 & 2.64 & 2.66 & 1 & 5.7 & 5.5 & 1.7 \\
\hline 4 & 2.68 & 4 & 2.60 & 2.45 & 2 & 6.3 & 4.8 & 2.0 \\
\hline
\end{tabular}

a Reactions were carried out at $60^{\circ} \mathrm{C}$ in benzene in sealed glass tubes under vacuum.

b Numbers correspond to those in Table II.

c After reprecipitation from benzene into methanol-diethyl ether $(1: 1)$ and washing.

${ }^{d}$ Measured in THF using a calibration curve with polystyrene.<smiles>C=C(C)C(=O)OCC(C)(C)[Si](C)(C)O[Si](OC)(O[SiH3])O[SiH3]</smiles>

2b

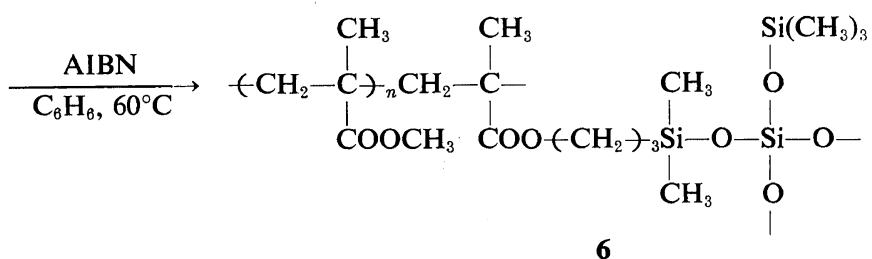

of $\mathbf{6}$ is sufficient to make PMMA surfaces water repellent. On the other hand, on the glass side, addition of 6 to PMMA shows little change of contact angles compared with PMMA alone. This result may be explained by assuming that the surface active polysiloxane, which shows water repellency, accumulated on the air side. The conditions of this surface accumulation are now under investigation in details.

Furthermore, the methacryloyl-end silicone oligomers with 7.6 end groups were examined as coating materials on various panels. Coated surfaces after irradiation with UV or electron beams showed water-repellency from the measurement of contact angles. Adhesion of surface coatings to the various panel surfaces was evaluated by the cross- cut test. These results are shown in Table VI. It can be seen from the table that the adhesion was strong in the following panel/ curing means combinations: polycarbonate/ UV irradiation and aluminum/electron beams. The study on the application of epoxy-end silicone oligomers is now continuing.

\section{EXPERIMENTAL}

\section{Materials}

Water glass (aqueous sodium silicate solution, JIS first class, $\mathrm{Na}_{2} \mathrm{O} \cdot 2.11 \mathrm{SiO}_{2}$ ) was commercially available and used without further purification. Allyl methacrylate, dichloromethylsilane, trimethylchlorosilane, dimethylchlorosilane, allyl glycidyl ether and all solvents were dried and distilled under a 


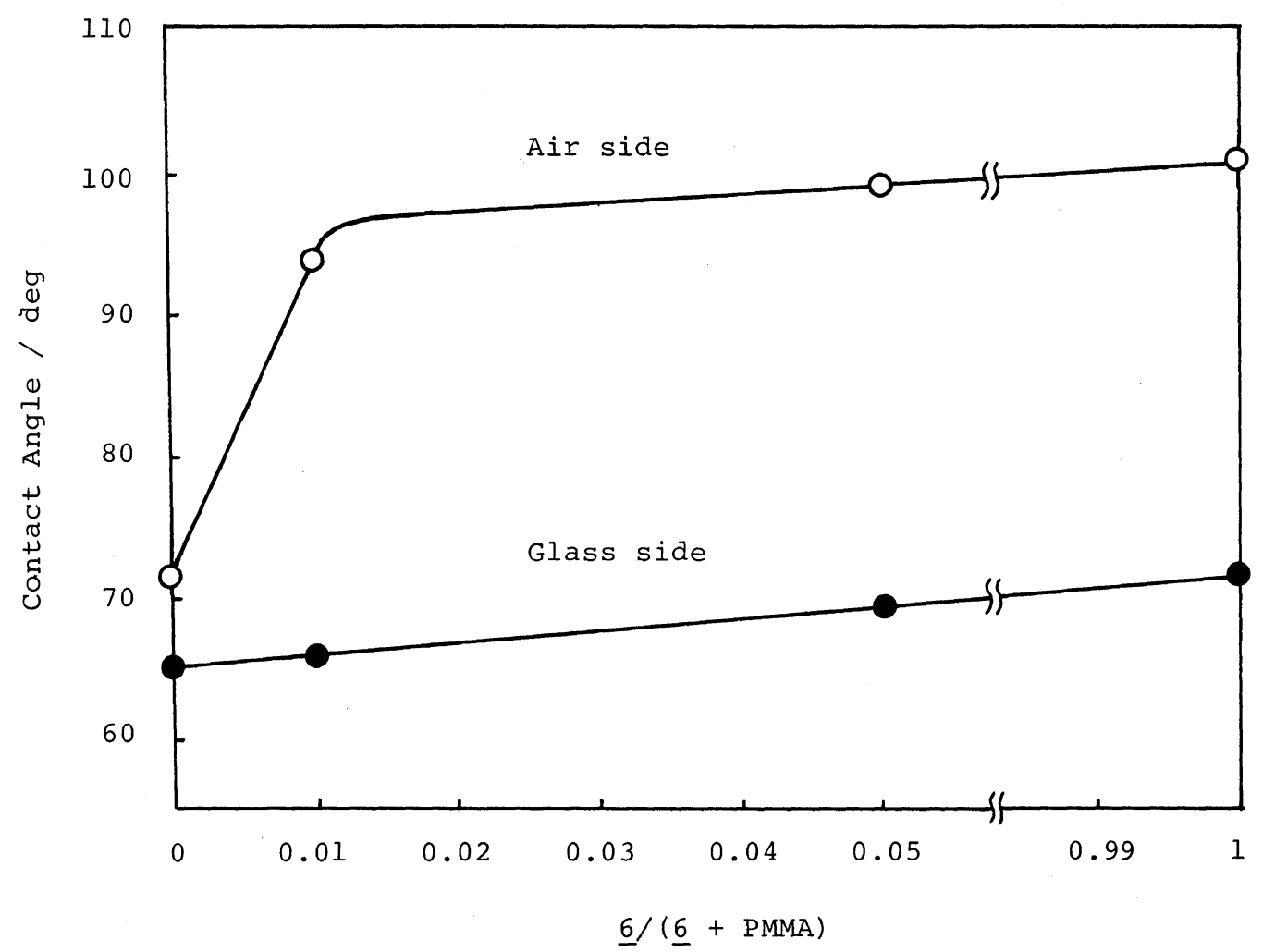

Figure 4. Contact angles for water.

Table VI. Cross-cut test of coating films $\mathrm{a}^{\mathrm{a}}$

\begin{tabular}{|c|c|c|c|c|}
\hline \multirow{2}{*}{ Curing } & \multicolumn{2}{|l|}{ Panel } & \multirow[b]{2}{*}{$\mathrm{Al}$} & \multirow[b]{2}{*}{ Steel } \\
\hline & Polycarbonate & PMMA & & \\
\hline $\begin{array}{l}\text { Electron } \\
\text { Beam }\end{array}$ & 0 & $x$ & $x$ & $\times$ \\
\hline UV & $\triangle$ & $\triangle$ & 0 & $x$ \\
\hline
\end{tabular}

$\bigcirc$, not stripped; $\triangle$, partially stripped; $\times$, stripped.

nitrogen atmosphere.

\section{Instruments}

IR spectra were obtained with a JEOL IRA-1. ${ }^{1} \mathrm{H}$ NMR spectra were obtained using a JEOL JNM PMX-60 (60 MHz). UV spectra were recorded on a Hitachi 124 double beam spectrophotometer. GPC was taken on a Toyo-Soda HLC-802 UR and calibrated with standard polystyrene samples. Molecular weights by VPO were determined in benzene using a Hitachi-115 instrument. Contact angles of a water droplet were measured at $20^{\circ} \mathrm{C}$ by a CA-A type goniometer of Kyowa Kagaku Co., Ltd. Electron beams were irradiated by a NP-ESH 150 (Japan Parkerizing Co., Ltd.).

Synthesis of Methyldichloro(3-methacryloyloxypropyl) silane

In a $50 \mathrm{ml}$ flask equipped with a dropping funnel, reflux condenser and thermometer, allyl methacrylate $(2.39 \mathrm{~g}, 18.9 \mathrm{mmol})$, platinum-carbon $\left(5 \times 10^{-4} \mathrm{~g}, 2.6 \times 10^{-4} \mathrm{~mol} \%\right)$ and a small amount of hydroquinone as the inhibitor were heated at $40^{\circ} \mathrm{C}$ for $30 \mathrm{~min}$ under a nitrogen atmosphere. Dichloromethylsilane was added from a dropping funnel and then the reaction mixture was heated at $60^{\circ} \mathrm{C}$ for $4 \mathrm{~h}$. Distillation $\left(\mathrm{bp}^{0.25} 61-63^{\circ} \mathrm{C}\right)$ gave methyldichloro(3-methacryloyloxypro- 
pyl)silane (1) as a colorless liquid. Yield was $2.19 \mathrm{~g}(48 \%)$. IR (neat): $1705\left(v_{\mathrm{C}=\mathrm{O}}\right), 1640$ $\left(v_{\mathrm{C}=\mathrm{C}}\right), \quad 1420$ and $900 \mathrm{~cm}^{-1}\left(\delta_{=\mathrm{CH}_{2}}\right),{ }^{1} \mathrm{H}$ NMR (in $\mathrm{CCl}_{4}$ ): $\delta 0.83$ (s, 3H, $\mathrm{Si}-\mathrm{CH}_{3}$ ), 1.27 (t, 2H, Si- $\left.\mathrm{CH}_{2}-\right), 1.86\left(\mathrm{~m}, 2 \mathrm{H},-\mathrm{CH}_{2}-\right), 2.00$ $\left(3 \mathrm{H}, \mathrm{CH}_{3}-\mathrm{C}=\right), 4.22\left(\mathrm{t}, 2 \mathrm{H},-\mathrm{COOCH}_{2}-\right)$, 5.54 and $6.08 \mathrm{ppm}\left(2 \mathrm{H}, \mathrm{CH}_{2}=\right)$.

\section{Preparation of Polymerizable Silicone Oligo- mers}

Method I. Water glass $(5.51 \mathrm{~g})$ in water $(20 \mathrm{ml})$ was added dropwise into aqueous sulfuric acid $\left(0.64 \mathrm{~mol} \mathrm{1}^{-1}, 30 \mathrm{ml}\right)$ with stirring. After $3 \mathrm{~h}$, THF $(50 \mathrm{ml})$ and $\mathrm{NaCl}(40 \mathrm{~g})$ were added and silicic acid was separated as a THF solution which was dried over $\mathrm{Na}_{2} \mathrm{SO}_{4}$. Silicic acid and a small amount of hydroquinone in THF were placed in a flask under a nitrogen atmosphere. From a dropping funnel, 1 $(0.61 \mathrm{~g}, 2.5 \mathrm{mmol})$ was added for $30 \mathrm{~min}$ and then the reaction mixture was stirred for $1 \mathrm{~h}$ at room temperature. Trimethylchlorosilane $(5.32 \mathrm{~g}, 49 \mathrm{mmol})$ was added and the mixture was stirred for $1 \mathrm{~h}$ at room temperature and then refluxed for $4 \mathrm{~h}$. Silicone oligomers (2a) were isolated by precipitation in $\mathrm{MeOH}-\mathrm{H}_{2} \mathrm{O}$ $(4: 1)$ and washing by water. Furthermore, this white solid of silicone oligomers was allowed to react with trimethylchlorosilane $(3.35 \mathrm{~g}$, $31 \mathrm{mmol}$ ) at room temperature for $1 \mathrm{~h}$ and then under reflux for $4 \mathrm{~h}$. Methacryloyl-end silicone oligomers (2b) were purified by reprecipitation using a mixed solvent described above. Yield was $2.17 \mathrm{~g}$.

Method II. Silicic acid was prepared by the same procedure as method I starting from $2.80 \mathrm{~g}(8.07 \mathrm{mmol})$ of water glass. Into silicic acid in THF, dimethylchlorosilane $(3.19 \mathrm{~g}$, $33.7 \mathrm{mmol}$ ) was added from a dropping funnel for $30 \mathrm{~min}$ in nitrogen. The mixture was stirred for $1 \mathrm{~h}$ at room temperature and trimethylchlorosilane $(2.33 \mathrm{~g}, 20.5 \mathrm{mmol})$ in THF $(20 \mathrm{ml})$ was then added. The resulting reaction mixture was stirred for $1 \mathrm{~h}$ at room temperature and refluxed for $3 \mathrm{~h}$. Precipitation in $\mathrm{MeOH}-\mathrm{H}_{2} \mathrm{O}$ (4:1) produced a white solid of 3 .
In a flask equipped with a dropping funnel, thermometer and reflux condenser, allyl methacrylate $\left(6.78 \times 10^{-2} \mathrm{~g}, 0.54 \mathrm{mmol}\right)$, platinum-carbon $\left(5 \times 10^{-4} \mathrm{~g}\right)$, a small amount of hydroquinone as the inhibitor and toluene $(1 \mathrm{ml})$ were heated at $40^{\circ} \mathrm{C}$ for $30 \mathrm{~min}$ under a nitrogen atmosphere. Silicone oligomers (3) in toluene were added dropwise and the mixture was heated at $160^{\circ} \mathrm{C}$ for $4 \mathrm{~h}$. The catalyst was removed by filtration and methacryloyl-end silicone oligomers (5a) were isolated by precipitation in $\mathrm{MeOH}-\mathrm{H}_{2} \mathrm{O}(4: 1)$. Yield was $0.25 \mathrm{~g}$.

Allyl glycidyl ether was also used instead of allyl methacrylate in a similar procedure.

\section{Copolymerization with MMA}

The copolymerization of methacryloyl-end silicone oligomers (2b) and methyl methacrylate was carried out in benzene at $60^{\circ} \mathrm{C}$ in the presence of AIBN in a sealed glass tube. The copolymer was isolated as a white solid by precipitation in $\mathrm{MeOH}$-diethyl ether $(1: 1)$ and purified by reprecipitation.

\section{Application of Silicone Oligomers}

Poly(methyl methacrylate) films containing various amounts of the copolymer $(0-$ $5 \mathrm{w} / \mathrm{w} \%$ ) were prepared by casting $2 \mathrm{w} / \mathrm{v} \%$ THF solution on clean glass slides, evaporating the solvent overnight and drying in vacuo. Contact angles of water on the air- and glasssides of the films were measured at $20^{\circ} \mathrm{C}$.

The test panels of glass or poly(ethylene terephthalate) were coated with a THF solution of methacryloyl-end silicone oligomers and irradiated with UV or electron beams. The cross cut test was carried out as follows. The coating films on the test panels was cut into 25 squares of $1 \times 1 \mathrm{~cm}$ by a knife. An adhesive tape was applied on the films and then torn off. The remaining coating films on the panels were examined.

\section{REFERENCES}

1. K. Ito, N. Usami, and Y. Yamashita, Macro- 
molecules, 13, 216 (1980); Y. Yamashita, J. Appl. Polym. Sci., Appl. Polym. Symp., 36, 193 (1981); Y. Yamashita, Y. Tsukahara, K. Ito, K. Okada, and Y. Tajima, Polym. Bull., 5, 335 (1981); Y. Yamashita, Y. Chujo, H. Kobayashi, and Y. Kawakami, Polym. Bull., 5, 361 (1981); Y. Kawakami, Y. Miki, T. Tsuda, R. A. N. Murthy, and Y. Yamashita, Polym. J., 14, 913 (1982); Y. Chujo, T. Tatsuda, and Y. Yamashita, Polym. Bull., 8, 239 (1982).

2. C. W. Lentz, Inorg. Chem., 3, 574 (1964).

3. S. Kohama, H. Inoue, and T. Yasuda, J. Polym. Sci., Polym. Chem. Ed., 18, 2357 (1980); Y. Abe, and T. Misono, J. Polym. Sci., Polym. Lett. Ed., 20, 205 (1982); Y. Abe, and T. Misono, J. Polym. Sci.,
Polym. Chem. Ed., 21, 41 (1983); M. Kajiwara, and N. Yamamoto, Polym. Commun., 24, 150 (1983); H. Inoue, and S. Kohama, J. Appl. Polym. Sci., 28, 2499 (1983).

4. B. R. Currell and J. R. Parsonage, J. Macromol. Sci., Chem., A16, 141 (1981).

5. H. Inoue and S. Kohama, J. Polym. Sci., Polym. Chem. Ed., 19, 759 (1981).

6. W. Noll, "Chemistry and Technology of Silicones," Academic Press, New York, N.Y., 1968.

7. R. S. Ward, Jr. and E. Nyilas, "Organometallic Polymers," Academic Press, New York, N.Y., 1978.

8. L. Le duc, L. P. Blanchard, and S. L. Malhotra, J. Macromol. Sci., Chem., A14, 389 (1980). 